\title{
Epigastric impedance: a non-invasive method for the assessment of gastric emptying and motility
}

\author{
G R McCLELLAND AND J A SUTTON \\ From the Human Pharmacology Unit, Beecham Pharmaceuticals Research Division, Harlow, Essex
}

SUmmary The impedance of the epigastrium to a $4 \mathrm{~mA}, 100 \mathrm{KHz}$ AC current increases while liquids of low electrical conductivity are being drunk. Logically, the decline which follows occurs as the liquid leaves the stomach. This impedance measurement of gastric emptying proved comparable with the dye dilution method. In a placebo controlled trial the impedance method recorded significantly faster gastric emptying rates after metoclopramide. The impedance trace contains regular activity in the $2-4$ cycle/min range consistent with gastric contractions. This non-invasive and technically simple method may thus provide a measure of simultaneous gastric emptying rates and motility.

Electrical impedance may be regarded as the $\mathrm{AC}$ equivalent of resistance to DC electric currents. Applied to the chest, impedance provides a sensitive method of monitoring volumes of respiratory air or intra-cardiac blood. We decided to investigate the possibility that applied to the epigastrium it would also detect changes in volume of gastric contents.

Using equipment of standard impedance design (Fig. 1) we repeatedly obtained increases in epigastric impedance of the order of 2 ohms when volunteers drank water. The rate of subsequent decline in impedance and its monoexponential pattern suggested that it might reflect gastric emptying. This was investigated in three ways: firstly, by simultaneous comparison with the dye dilution method of George ${ }^{1}$ as modified by Hurwitz $;^{2}$ secondly, by examination of the effects of changing meal conductivity and of gastric secretion; and thirdly by measurement of the effects of the gastric stimulant, metoclopramide.

We had observed that impedance traces frequently contained regular waves lasting approximately 20 seconds which were distinct from respiration interference. Characteristically they became more prominent after meals which, with their periodicity, suggested that they were linked to gastric contractions. Therefore, we quantified

Address for correspondence: Mr G R McClelland, Beecham Pharmaceuticals Research Division, Coldharbour Road. The Pinnacles, Harlow, Essex CM19 5AD.

Received for publication 27 July 1984 this activity before and after meals, with and without metoclopramide.

\section{Methods}

SUBJECTS

In all experiments subjects were healthy volunteers from an established panel who gave written, informed consent before the study. Experiments were all carried out between 0830 and 1030 hours, subjects having fasted overnight. Measurements were made while subjects lay semisupine at approximately $45^{\circ}$ with their legs stretched out before them.

\section{COMPARISON WITH DYE DILUTION}

Two aluminium foil tape electrodes (3M), thinly smeared with contact jelly (Cardiogel, Cambridge), were placed adjacent to a line from the umbilicus to the midpoint of the costal margin - that is, from xiphisternum to caudal extremity. Two more were placed by eye where they would have appeared virtually superimposed in a hypothetical AP radiograph. One of each pair was used for input of $4 \mathrm{~mA}$ peak-to-peak constant current at $100 \mathrm{KHz}$, the other pair recorded consequent voltage variations. Circuitry is described in Fig. 1 and included isolation circuitry for volunteer safety. Low pass filtering $(-3 \mathrm{~dB}$ at $0 \cdot 1 \mathrm{~Hz}$ ) excluded cardiac but not respiratory signal interference. An offset voltage control allowed for differences in basal body impedance. The output signal was recorded on a Bryan's 2900 series chart 


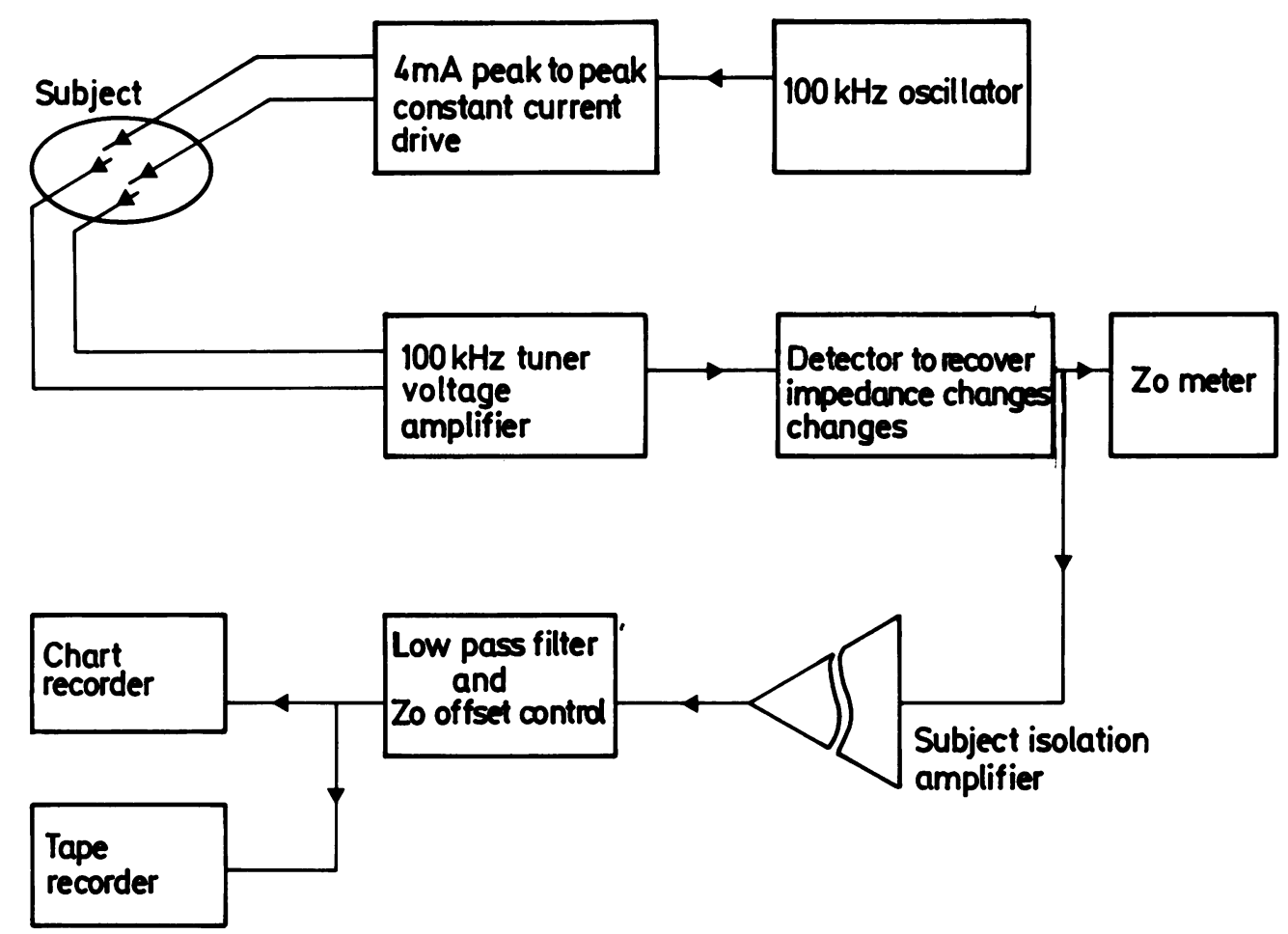

Fig. 1 Diagrammatic representation of epigastric impedance equipment.

recorder. The deflection height of gastric filling (equivalent to Point $\mathrm{C}$, Fig. 2) above the baseline was measured by ruler and designated $100 \%$. The deflection remaining at 5,10 , and 20 minutes was measured also.

Before the study the subjects were intubated (Warne, 18FG) and the gastric contents aspirated after washing with water. 'Meals' of $750 \mathrm{ml}$ distilled water or $5 \%$ glucose at $37^{\circ} \mathrm{C}$ were instilled down the tube through a funnel held at a constant height of $2.4 \mathrm{~m}$. Phenol red solutions $(50 \mathrm{ml}$ of 1,2 , and $4 \mathrm{mg} / \mathrm{ml}$ ) were injected down the tube 5,10 , and 20 minutes after gastric filling was complete. Before and after these injections $25 \mathrm{ml}$ of gastric content were withdrawn for assay. Mixing was facilitated by three vigorous aspirationreinstillations of $50 \mathrm{ml}$. Concentrations of phenol red were determined spectrophotometrically at 560 $\mathrm{m} \mu$. Gastric content volume $\left(\mathrm{V}_{1}\right)$ was calculated as:

$$
\mathrm{V}_{1}=\frac{\mathrm{V}_{2}\left(\mathrm{C}_{2}-\mathrm{C}_{3}\right)}{\mathrm{C}_{3}-\mathrm{C}_{1}}
$$

where $V_{2}$ is the volume of phenol red added and $C_{2}$ the concentration therein; $C_{1}$ and $C_{3}$ are the

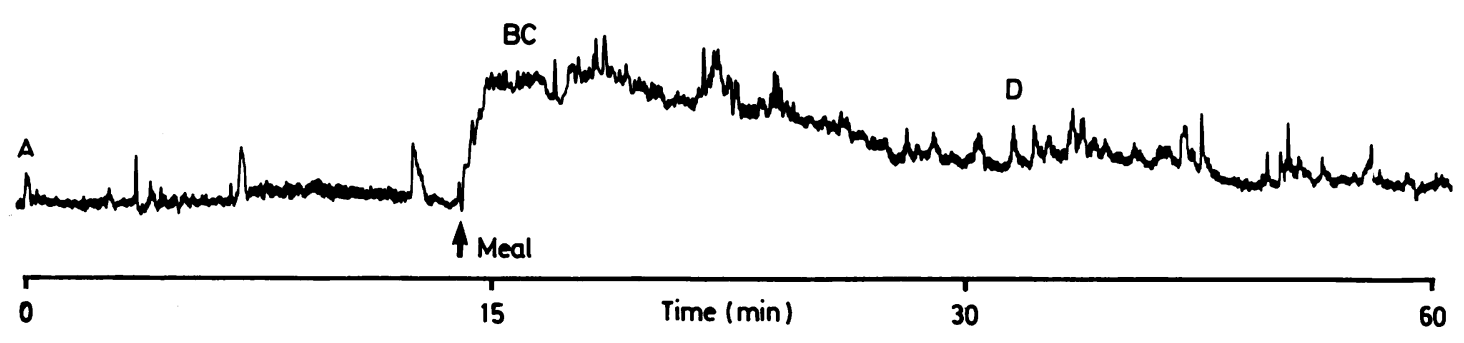

Fig. 2 Example of a typical epigastric impedance trace. 
concentrations in the pre- and post-injection samples respectively.

Four men (aged 24-38 years) and one woman (aged 25 years) participated in this experiment.

\section{CONDUCTIVITY EXPERIMENTS}

It was found that simple adhesive, silver/silver chloride electrodes (Hewlett Packard, type 14445A) provided better contact, reduced typical baseline impedance from about $20 \Omega$ to $10-12 \Omega$ and produced stable baselines (Fig. 2). They were positioned as follows: anteriorly the input electrode was placed one third of the distance along a line $\mathrm{xu}$ from the margin of the xiphisternum to the centre of the umbilicus $(\mathrm{xu} / 3)$; the recording electrode was an equal distance further caudally (2xu/3) and laterally (Fig. 3). On the back the recording electrode position remained at the $\mathrm{xu} / 3$ level but $\mathrm{xu} / 2$ to the left of the midline while the input electrode level was at $2 \mathrm{xu} / 3$ and $\mathrm{xu} /$ 6 to the left. These positions were judged by eye and tape measure with the volunteers standing up.

Two male volunteers (aged 27 and 30 years) consumed $600 \mathrm{ml}$ of nine different liquid meals and two semi-solid meals, in random order. Conductivities and deflections produced by each meal are listed in Table 1.

The $\mathrm{pH}$ and conductivity changes of gastric contents after $110 \mathrm{ml}$ of orange 'Quosh' in $500 \mathrm{ml}$ water were measured in one volunteer (40 year old man). Aspirate volumes of $12-20 \mathrm{ml}$ were taken at regular intervals after the meal, and within three hours of sampling, conductivity (Howe Model 2051) and pH (Orion Model 201) were measured.

\section{METOCLOPRAMIDE EXPERIMENT}

Six men and two women participated in this experiment (mean age $\pm S D, 29 \pm 4.8$ years, body weight $66 \cdot 6 \pm 7 \cdot 8 \mathrm{~kg}$ and height $1.74 \pm 0.05 \mathrm{~m}$ ).

Two meals comprising $130 \mathrm{ml}$ orange flavoured 'Quosh' and $620 \mathrm{ml}$ tap water at room temperature, were drunk, the test drug being given between them. Meal A was drunk when 20 minutes of stable impedance baseline was obtained. It provided a check that volunteers were emptying normally. When impedance has returned to baseline volunteers were allowed up for a rest and to empty their bladders. When they had resettled, $10 \mathrm{mg}$ metoclopramide (Maxolon, Beecham), $0 \cdot 6$ $\mathrm{mg}$ atropine sulphate (Antigen) or saline placebo, were injected as evenly as possible over two minutes into a hand vein.

Meal B was swallowed five minutes later. The maximum initial impedance deflection was measured from the trace after further low-pass filtering. The percentage remaining at each minute, for 30 minutes, was fitted to the monoexponential function $\mathrm{ae}^{(-\mathrm{bx})}$ and the time to achieve $50 \%$ emptying $\left(t_{\frac{1}{2}}\right)$ calculated from it. The impedance output was also recorded on magnetic tape (Racal) and processed by a minicomputer (PDP 11/40) for display on a VDU, whence five
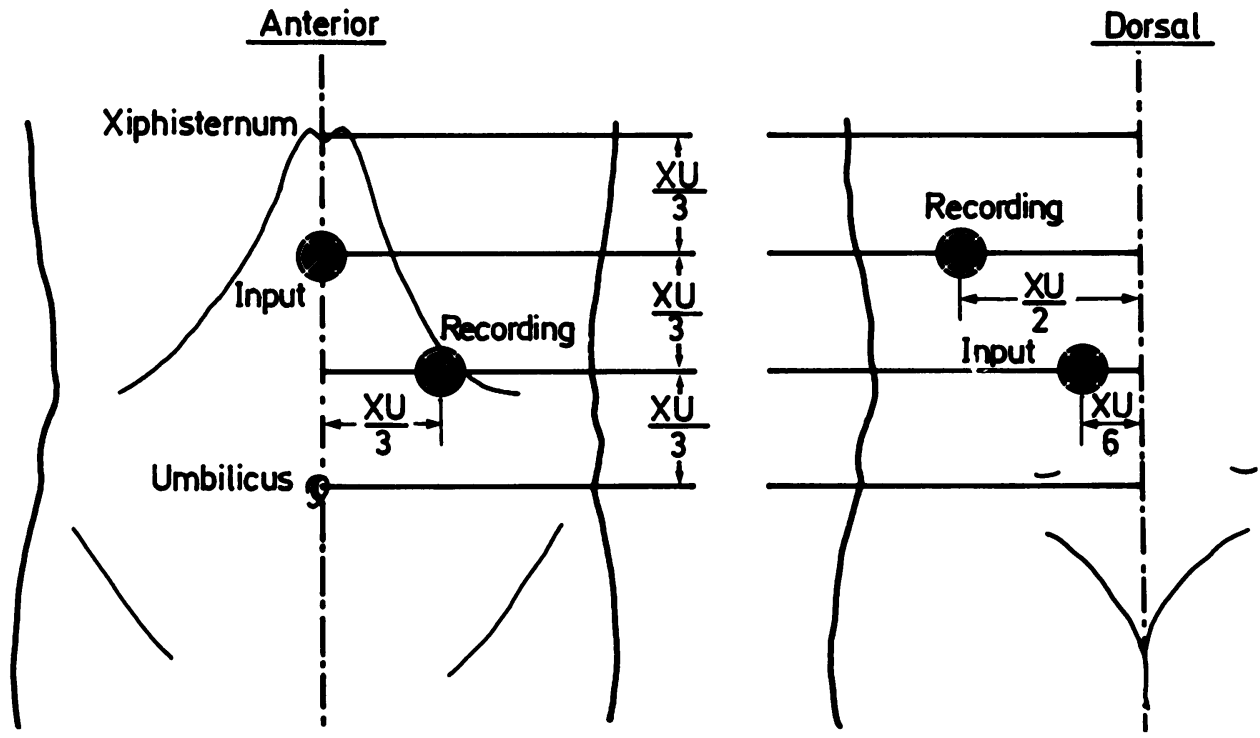

Fig. 3 Standard electrode placement. 
Table 1 Impedance changes produced by 11 meals of different conductivity in two normal volunteers

\begin{tabular}{|c|c|c|c|}
\hline Meal $(600 \mathrm{ml})$ & Conductivity ( $\mathrm{mS})$ & $\begin{array}{l}\text { Volunteer } 1 \\
\text { impedance change }(\Omega)\end{array}$ & $\begin{array}{l}\text { Volunteer } 2 \\
\text { impedance change ( } \Omega)\end{array}$ \\
\hline 'Hycal', low clectrolyte & $0 \cdot 19$ & $1 \cdot 33$ & 0.97 \\
\hline Lemonade & $1 \cdot 00$ & $2 \cdot 05$ & 0.97 \\
\hline Orange squash - 'Quosh' & $1 \cdot 10$ & $1 \cdot 15$ & $1 \cdot 13$ \\
\hline Lucozade & $1 \cdot 65$ & $1 \cdot 51$ & 0.67 \\
\hline SMA baby milk & $1 \cdot 80$ & $1 \cdot 56$ & 0.69 \\
\hline Lemon squash + two whisked eggs & $1 \cdot 85$ & $2 \cdot 10$ & $1 \cdot 72$ \\
\hline MCTI (low lactose, high fat) & $2 \cdot 27$ & 0.77 & $0 \cdot 74$ \\
\hline Lemonade + two whisked eggs & $2 \cdot 28$ & $1 \cdot 59$ & 0.97 \\
\hline Soya protein milk (Soyvita) & $2 \cdot 30$ & $0 \cdot 79$ & 0.90 \\
\hline Instant mashed potato (Yeoman) & $9 \cdot 35$ & $\downarrow$ & $\downarrow$ \\
\hline Chicken soup (Heinz) & $11 \cdot 90$ & $\downarrow$ & $\downarrow$ \\
\hline
\end{tabular}

$\downarrow$ indicates no positive deflection.

minute samples of trace were selected by light pen. One sample was taken from a premeal baseline portion and three consecutive samples after the meal $(0-5,6-11$ and 12-17 minutes approximately). These four samples were then analysed using Fourier Analysis.

\section{Results}

\section{DYE DILUTION}

The percentage of each meal remaining is shown in Fig. 4. There was no statistically significant difference between the two methods at any time for either meal. Both detected a significantly slower emptying rate for $5 \%$ glucose solution than water (impedance $\mathrm{p}<0.05$ at 20 minutes and dye dilution $\mathrm{p}<0.05$ at 10 minutes, Student's paired $t$ test).

\section{CONDUCTIVITY EXPERIMENTS}

Comparison of the impedance deflections for liquid meals constant volume but differing electroconductivity yielded no consistent relationship (Table 1).

The simultaneous $\mathrm{pH}$, conductivity and impedance measurements in one volunteer (Table 2) showed a fall in $\mathrm{pH}$ and impedance after the meal while conductivity increased. No reciprocal linear relationship between impedance and conductivity was evident.

\section{METOCLOPRAMIDE EXPERIMENT}

The impedance deflection (Table 3 ) and the calculated $t \frac{1}{2}$ (Table 4 ) reveal highly significant differences between volunteers $(p<0.0001$ and $\mathrm{p}<0.001$ respectively, analysis of variance). The variation within subjects is illustrated in Figure 5 in which the mean emptying rates of meals (a) and (b) on the two baseline days, and meal (a) on treatment days, are plotted against time for each volunteer. This variation did not preclude distinguishing between fast and slow emptiers. Thus, volunteer 4 was relatively slow with a mean $t \frac{1}{2}$ of $16 \cdot 5 \pm 3 \cdot 0$ minutes, while volunteer 5 at $4.75 \pm 2.7$ minutes

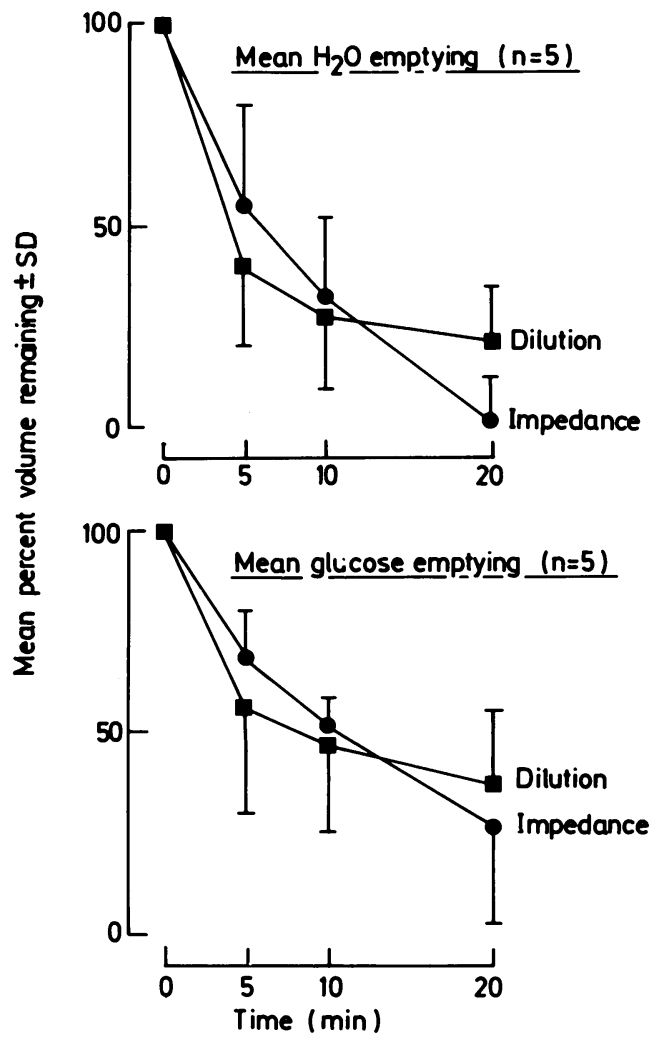

Fig. 4 Comparison of the epigastric impedance method with that of dye dilution. 
Table 2 Intragastric conductivity and $p H$ changes after $500 \mathrm{ml}$ orange squash

\begin{tabular}{llll}
\hline $\begin{array}{l}\text { Sample time } \\
(\text { min) }\end{array}$ & $p H$ & $\begin{array}{l}\text { Conductivity } \\
(\mathrm{mS})\end{array}$ & $\begin{array}{l}\text { Impedance } \\
(\Omega)\end{array}$ \\
\hline Premeal & $5 \cdot(0)$ & $3 \cdot 58^{*}$ & - \\
0 & $3 \cdot 20$ & $2 \cdot 23$ & $1 \cdot 92$ \\
2 & $2 \cdot 80$ & $2 \cdot 51$ & $1 \cdot 51$ \\
5 & $2 \cdot 95$ & $2 \cdot 55$ & $1 \cdot 10$ \\
8 & $2 \cdot 30$ & $2 \cdot 94$ & $0 \cdot 85$ \\
10 & $2 \cdot 20$ & $3 \cdot 40$ & $0 \cdot 51$ \\
12 & $2 \cdot 05$ & $4 \cdot 65$ & $0 \cdot 26$ \\
15 & 1.95 & $6 \cdot 54$ & $0 \cdot(08$ \\
18 & $1 \cdot 85$ & $6 \cdot 78$ & $0 \cdot 13$ \\
20 & $1 \cdot 80$ & $8 \cdot 38$ & 0 \\
\hline
\end{tabular}

* This sample contained mucus which produced an erratic reading.

was fast. In the slower subject the postmetoclopramide emptying rate was the fastest but in the faster subject there was no difference between treatments. Overall there was a statistically significant difference in $t_{\frac{1}{2}}$ between the three treatments $(p=0.04$, analysis of variance $)$ with metoclopramide significantly different from both atropine and placebo at the 5\% level (Duncan's multiple range test).

According to Fourier analysis the impedance signal power at 2-4 cycle/min increased after a meal. This is illustrated in Fig. 6 for volunteers 4 and 5. The faster emptier doubled the power within all three postmeal sampling periods compared with the premeal value. In the slower emptier the increase was minimal, being $12 \%$ in the 12-17 minute postmeal sample only. Volunteer 7 was exceptional and consistently produced little or no increase in power after a meal.

Group mean levels of power within the 2-4 cycle/ min waveband according to Fourier analysis are compared in Fig. 7. After metoclopramide the power doubled in the second sample after the meal which contrasts with the lack of increase after placebo and atropine.
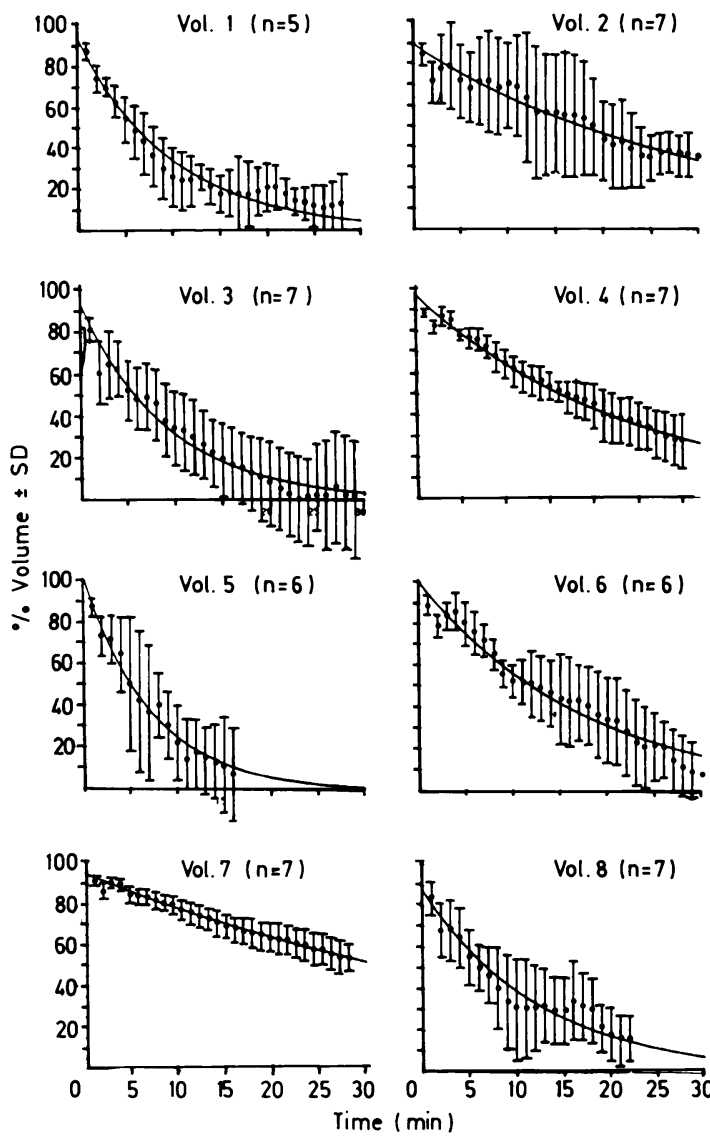

Vol. $8(n=7)$

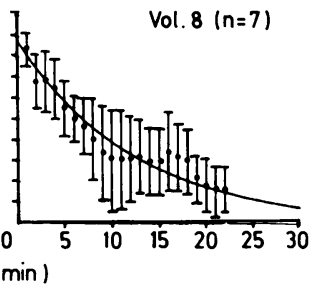

Fig. 5 Mean baseline gastric emptying rates for each volunteer.

\section{Discussion}

From the very first experiment we have found considerable increases in epigastric impedance during the consumption of liquid meals which have low electrical conductivity. The timing and

Table 3 Impedance deflection $(\Omega)$ to $750 \mathrm{ml}$ orange squash

\begin{tabular}{|c|c|c|c|c|c|c|c|c|c|c|c|c|}
\hline \multirow{2}{*}{$\begin{array}{l}\text { Volunteer } \\
\text { number }\end{array}$} & \multicolumn{4}{|c|}{ Baseline sessions } & \multicolumn{2}{|c|}{ Placebo } & \multicolumn{2}{|c|}{ Metoclopramide } & \multicolumn{2}{|c|}{ Atropine } & \multirow[b]{2}{*}{ Mean } & \multirow[b]{2}{*}{$S D$} \\
\hline & $I A$ & $I B$ & $2 A$ & $2 B$ & $A$ & $B$ & $A$ & $B$ & $A$ & $B$ & & \\
\hline 1 & $1 \cdot 76$ & $2 \cdot 76$ & 1.63 & $2 \cdot 10$ & $1 \cdot 61$ & 1.73 & $1 \cdot 63$ & $2 \cdot 54$ & $2 \cdot 39$ & 3.88 & $2 \cdot 20$ & 0.72 \\
\hline 2 & $1 \cdot 61$ & $2 \cdot 34$ & $2 \cdot 73$ & $2 \cdot 44$ & $3 \cdot 66$ & $3 \cdot 22$ & $2 \cdot 80$ & $2 \cdot 37$ & $3 \cdot 76$ & $2 \cdot 32$ & $2 \cdot 72$ & 0.66 \\
\hline 3 & $1 \cdot 73$ & $1 \cdot 37$ & $1 \cdot 66$ & 1.73 & $1 \cdot 76$ & $1 \cdot 34$ & $2 \cdot 27$ & $1 \cdot 71$ & $2 \cdot 07$ & $2 \cdot 34$ & $1 \cdot 80$ & $0 \cdot 34$ \\
\hline 4 & $3 \cdot 78$ & $3 \cdot 63$ & 1.95 & 1.90 & $3 \cdot 15$ & $2 \cdot 83$ & $3 \cdot 22$ & $2 \cdot 41$ & $3 \cdot 54$ & 3.44 & 2.99 & 0.69 \\
\hline 5 & $1 \cdot 39$ & $(0.59$ & $1 \cdot 83$ & $1 \cdot 24$ & $1 \cdot 46$ & 0.78 & $1 \cdot 61$ & 0.95 & $3 \cdot 54$ & 3.44 & 1.68 & $1 \cdot(12$ \\
\hline 6 & 1.61 & $2 \cdot 34$ & $2 \cdot 12$ & 1.44 & 1.90 & $1 \cdot 10$ & $3 \cdot 22$ & $2 \cdot 39$ & 1.98 & 1.98 & $2 \cdot(0) 1$ & 0.58 \\
\hline 7 & 3.49 & $3 \cdot 58$ & $4 \cdot 24$ & $4 \cdot 39$ & 4.39 & 3.73 & $5 \cdot 20$ & 4.83 & $4 \cdot 24$ & 4.39 & $4 \cdot 26$ & 0.52 \\
\hline 8 & $2 \cdot 46$ & $(0.61$ & $2 \cdot 68$ & $1 \cdot 83$ & $2 \cdot 63$ & $3 \cdot 34$ & $2 \cdot 17$ & $1 \cdot 76$ & $3 \cdot 27$ & 0.93 & $2 \cdot 17$ & 0.91 \\
\hline
\end{tabular}


Table 4 Half-emptying times (minutes) after $750 \mathrm{ml}$ orange squash

\begin{tabular}{|c|c|c|c|c|c|c|c|c|c|c|}
\hline \multirow{2}{*}{$\begin{array}{l}\text { Volunteer } \\
\text { number }\end{array}$} & \multicolumn{4}{|c|}{ Baseline sessions } & \multicolumn{2}{|c|}{ Placebo } & \multicolumn{2}{|c|}{ Metoclopramide } & \multicolumn{2}{|c|}{ Atropine } \\
\hline & $I A$ & $I B$ & $2 A$ & $2 B$ & $A$ & $B$ & $A$ & $B$ & $A$ & $B$ \\
\hline 1 & $3 \cdot 80$ & $5 \cdot 45$ & $7 \cdot 10$ & $*$ & 8.48 & 3.99 & $4 \cdot 83$ & $4 \cdot 86$ & $*$ & $12 \cdot 59$ \\
\hline 2 & $25 \cdot 63$ & $7 \cdot 68$ & $17 \cdot 74$ & $35 \cdot 01$ & $10 \cdot 40$ & $11 \cdot 17$ & $36 \cdot 76$ & $4 \cdot 08$ & $12 \cdot 15$ & $7 \cdot 70$ \\
\hline 3 & $4 \cdot 24$ & $8 \cdot(12$ & $6 \cdot(12$ & $9 \cdot 16$ & $2 \cdot 19$ & $3 \cdot 62$ & $4 \cdot 44$ & 4.96 & $12 \cdot 18$ & $6 \cdot 24$ \\
\hline 4 & 16.43 & 12.97 & $21 \cdot 40$ & $17 \cdot 33$ & $18 \cdot 80$ & $33 \cdot 34$ & $14 \cdot 09$ & $9 \cdot 44$ & $14 \cdot 24$ & $22 \cdot(16$ \\
\hline 6 & $*$ & $17 \cdot 30$ & $21 \cdot 96$ & $8 \cdot 75$ & $9 \cdot(1) 2$ & $10 \cdot 23$ & $10 \cdot 81$ & $4 \cdot 27$ & $11 \cdot 88$ & $14 \cdot 63$ \\
\hline 7 & $28 \cdot 7()$ & $24 \cdot 50$ & $41 \cdot 64$ & $32 \cdot 39$ & $33 \cdot 75$ & $33 \cdot 07$ & $39 \cdot 44$ & 23.96 & $55 \cdot 22$ & $44 \cdot 8()$ \\
\hline 8 & $5 \cdot 33$ & 2.93 & $5 \cdot 77$ & $19 \cdot 56$ & $4 \cdot 21$ & $9 \cdot 16$ & 8.53 & 5.94 & $7 \cdot 73$ & $6 \cdot 08$ \\
\hline Mcan & $12 \cdot 74$ & $10 \cdot 11$ & $16 \cdot 42$ & $20 \cdot 37$ & $11 \cdot 54$ & $13 \cdot 40$ & $15 \cdot 38$ & $7 \cdot 55$ & $16 \cdot 84$ & $14 \cdot 63$ \\
\hline $\mathrm{SD}$ & $10 \cdot 81$ & $7 \cdot 31$ & $12 \cdot 23$ & $11 \cdot 22$ & $10 \cdot 21$ & $12 \cdot 63$ & $14 \cdot 46$ & 6.91 & $17 \cdot 24$ & $13 \cdot 62$ \\
\hline
\end{tabular}

* Recording interrupted by movement or discomfiture caused by full urinary bladder etc.

significance of conductivity - milk, for example, produces no deflection - leave no room for douḅt that the impedance method detects gastric filling.

The dye dilution comparison produced results in sufficiently close agreement on emptying rates for us to conclude that epigastric impedance should be explored further. Thus, in the pharmacological test of the method metoclopramide significantly reduced the group mean $t \frac{1}{2}$. This reduction occurred in the four slowest emptiers on placebo, a result which agrees with published dye dilution, ${ }^{34}$ radiology ${ }^{5-7}$ a radio-isotope labelled meal, ${ }^{8}$ ultrasound, ${ }^{9}$ and paracetamol absorption rates. ${ }^{11}$

Atropine $0.6 \mathrm{mg}$ intravenously did not affect the group mean $t^{\frac{1}{2}}$ time. This dose was explored because it was unlikely to induce unacceptable cardiovascular effects in volunteers, ${ }^{11}$ and is frequently used in anaesthesia. This result accords with the apparent majority of opinion on the effects of $0.6 \mathrm{mg}$ atropine. ${ }^{11}$

The rate at which gastric contractions occur was originally described by Alvarez in $1922^{12}$ and has been quantified in the electrogastrogram (EGG) from cutaneous electrodes in animals and man, using Fourier analysis. ${ }^{13-15}$ In man the average increase in the power of 3 cycle/min activity after a meal was $150 \%$ according to Brown et al ${ }^{13}$ and fivefold according to van der Schee et al. ${ }^{15}$ During this study the power in the 2-4 cycle/min waveband approximately doubled immediately after a placebo or atropine dose meal. This occurred at 2.4 cycles/min or less, which tended to reduce the
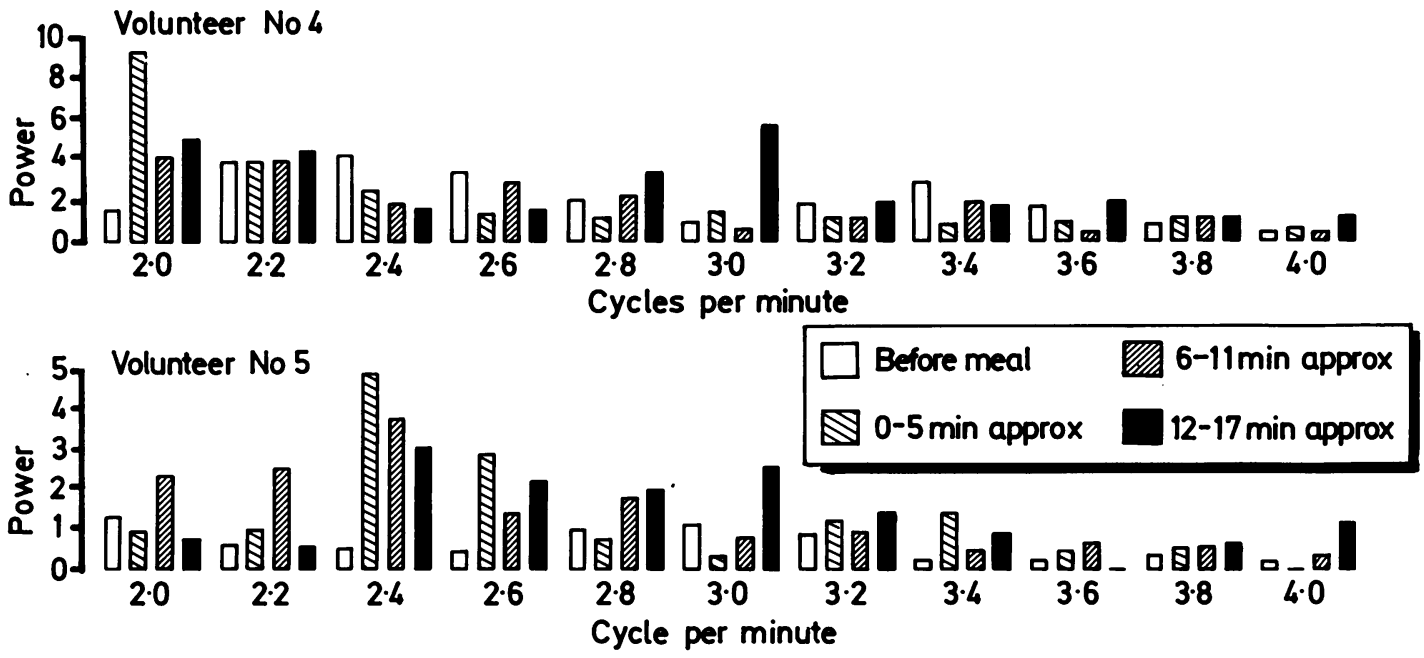

Fig. 6 Impedance power spectrum in a slow and a fast emptying volunteer after a liquid meal. 


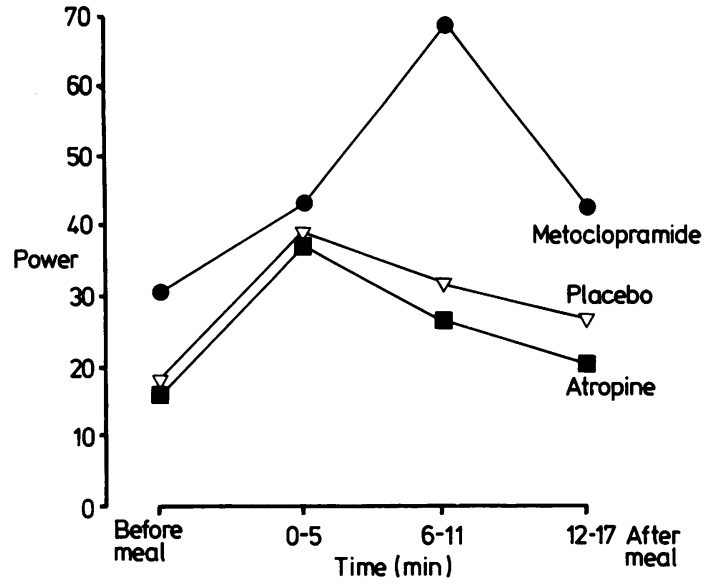

Fig. 7 Group mean power of gastric contractions after administration of placebo, metoclopramide and atropine.

average frequency. A similar reduction has been observed by others using the EGG. ${ }^{15-17}$ For example, van der Schee ${ }^{15}$ reported the average frequency decreased from $2 \cdot 88 \mathrm{cycles} / \mathrm{min}$ to $2 \cdot 34$.

Meals taken after metoclopramide produced greater and more prolonged increases which we consider to be biologically significant although not statistically so. (Standard tests of significance are not applicable to complex signals when, as in the case of the EGG intersubject variation is large and the distribution of frequencies in the spectrum is not normal.) Pressure transducers have been used to record contractile activity after metoclopramide $^{1819}$ when significant increases were found compared with placebo. The impedance increase observed in 2-4 cycle/min activity during this study therefore echoes this finding.

The low level of 2-4 cycle/min activity in volunteer 7 was exceptional in this and in subsequent studies. The slow emptying rate, however, was confirmed later by the dye dilution method. This volunteer may have pathologically slow emptying as several months after these experiments she developed thyrotoxicosis, the examination and follow up of which revealed thyroid auto-antibodies, relatively low gastric acid output and vitamin B12 deficiency. The volunteer also had a similar maternal family history.

During the study it became apparent that faster emptying rates were associated with greater 2-4 cycle/min power. A calculation of the correlation between these for all non-treatment meals disclosed a highly significant logarithmic relationship $\left(r^{2}=0.91, p=0.001\right)$. We observe, however, that this high correlation was largely because of volunteer 7 and so we regard it as encouraging, though not conclusive evidence that this activity is directly related to gastric contractions.

The orange squash meal is of simple constitution. Such meals leave the stomach rapidly, which is important when volunteers must lie still throughout recordings. Furthermore, and as our preliminary study apparently indicated, it is unlikely to stimulate gastric secretions to the point of significantly reducing the impedance of the epigastric region.

In conclusion, it was found that a liquid meal of low conductivity produces a reproducible increase in the impedance of the epigastric region. This declines subsequently in an exponential manner and at a rate which is consistent with known gastric emptying patterns. After metoclopramide the apparent rate of emptying calculated by this method increased. This increase occurred in the slower emptiers on placebo, which is consistent with predictions from established methods.

The impedance trace contains considerable activity at 2-4 cycles/min; frequencies at which stomach contractions are known to occur. This activity increased after a liquid meal consistent with the physiological prediction. The slight shift to the left in mean frequency is also consistent with electrogastrographic findings. After metoclopramide it was increased further which is consistent with the predicted pharmacological response.

Epigastric impedance offers a simple and entirely non-invasive method of measuring gastric emptying rates and gives an immediate result. It is possible that it may detect gastric contractile activity also. We conclude that the method is worthy of further investigation.

We wish to thank Messrs G R Francis and K E E Pettitt for the design and construction of the impedance equipment; D H Turner and S M Cooper for phenol red assays and advice during the dye dilution experiment; Sister M E Blamey for invaluable clinical assistance and Mrs J Dowsett for production of the manuscript.

\section{References}

1 George JD. A new method for measuring the rate of gastric emptying: the double sampling test meal. Gut 1968; 9: 237-42.

2 Hurwitz A. Measuring gastric volumes by dye dilution. Gut 1981; 22: 85-93. 
3 Martin PD, Scobie BA. Metoclopramide and gastric emptying. NZ Med J 1967; 67: 494.

4 Mearoff JC. The effect of metoclopramide on human gastric emptying and secretion. Acta Gastroenterol Latinoam 1974; 6: 55.

5 James WB, Hume R. Action of metoclopramide on gastric emptying and small bowel transit time. Gut 1968; 9: 203.

6 Howells TN, Khanam T, Kreel L, Seymour C, Oliver B, Davies JAH. Pharmacological emptying of the stomach with metoclopramide. $B r \operatorname{Med} J$ 1971; 2: 558-60.

7 Kreel L. The use of metoclopramide in radiology. Postgrad Med J 1972; 49: 42.

8 Hancock BD, Bowen-Jones D, Dixon R, Dymock IW, Cowley DJ. The effect of metoclopramide on gastric emptying of solid meals. Gut 1974; 15: 462.

9 Bateman DN, Whittingham TA. The measurement of gastric emptying by real-time ultrasound. Gut 1982; 23: $524-7$.

10 Nimmo J, Heading RC, Tothill P, Prescott LF. Pharmacological modification of gastric emptying: effects of propantheline and metoclopramide on paracetamol absorption. Br Med J 1973; 1: 587-9.

11 Weiner $\mathrm{N}$. Atropine scopolamine and related antimuscarinic drugs. In: Gilman GA, Goodman LS, Gilman A, eds. The pharmacological basis of therapeutics. 1980: 120-37.

12 Alvarez WC. The electrogastrogram and what it shows. JAMA 1922; 78: 1116-9.

13 Brown BH, Smallwood RH, Duthie HL, Stoddard CJ. Intestinal smooth muscle electrical potentials recorded from surface electrodes. Med Bio Eng Comput 1975; 13: $97-103$.

14 Smout AJPM, van der Schee EJ, Grashuis JL. Postprandial and interdigestive gastric electrical activity in the dog recorded by means of cutaneous electrodes. In: Christensen J, ed. Gastrointestinal motility. New York: Raven Press, 1980: 187-94.

15 van der Schee EJ, Smout AJPM, Grashuis JL. Application of running spectrum analysis to electrogastrographic signals recorded from dog and man. In: Weinbeck $\mathrm{H}$, ed. Motility of the digestive tract. New York: Raven Press, 1982: 241-50.

16 Smallwood RH. Gastrointestinal electrical activity from surface electrodes. Thesis: University of Sheffield, 1976.

17 Smout AJPM. Myoelectric activity of the stomach; gastroelectromyography and electrogastrography. Thesis, Rotterdam, The Netherlands: Erasmus University, 1980.

18 Johnson AG. The action of metoclopramide on human gastroduodenal motility. Gut 1971; 12: 421.

19 Eisner M. Effect of metoclopramide on gastrointestinal motility in man. Dig Dis 1971; 16: 409. 